\title{
LIMITACÃO DA RESPONSABILIDADE CIVIL RELATIVA AO TRANSPORTE DE PASSAGEIROS E ÀS SUAS BAGAGENS POR VIA MARÍTIMA: CONVENCÃO DE ATENAS 2002
}

\author{
LIMITATION OF CIVIL LIABILITY RELATING TO THE CARRIAGE OF PASSENGERS AND THEIR \\ LUGGAGE BY SEA: ATHENS CONVENTION 2002
}
LIMITACIÓN DE LA RESPONSABILIDAD CIVIL RELATIVA AL TRANSPORTE DE PASAJEROS Y SUS EQUIPAJES POR MAR: CONVENCIÓN DE ATENAS 2002

Norman A. Martínez Gutiérrez²

Priscila Gonçalves de Castro ${ }^{3}$

RESUMO

Este artigo trata da limitação da responsabilidade civil relativa ao transporte de passageiros e às suas bagagens por via marítima, por meio do estudo da Convenção de Atenas Relativa ao Transporte de Passageiros e suas Bagagens por Via Marítima de 2002 (Convenção de Atenas 2002). Busca-se tecer algumas considerações gerais, inicialmente acerca da responsabilidade civil, trazendo a forma com que o tema é tratado em relação ao transporte de passageiros por via marítima. Na sequência, discorre-se sobre o conceito de tratado internacional, as fases necessárias para que ele possa vir a adquirir executoriedade e a forma com que ele será recepcionado no ordenamento jurídico interno. Ato contínuo, buscou-se conhecer a interpretação dos tribunais nacionais sobre o tema. Na segunda parte do artigo, investigouse a Convenção de Atenas 2002, informando os países que já a adotaram, bem como o conteúdo e as peculiaridades elencadas neste acordo. Adota-se o método indutivo e as técnicas do referente, categorias e conceitos operacionais, além de pesquisa de fontes bibliográficas.

PALAVRAS-CHAVE: Convenção de Atenas 2002. Limitação da Responsabilidade Civil. Transporte Marítimo.

\section{ABSTRACT}

This article deals with the limitation of civil liability relating to the maritime transport of passengers and their belongings: the Athens Convention Relating to the Carriage of Passengers and their Luggage by

1 Agradecemos os comentários e a colaboração feitos pelo Professor Dr. Osvaldo Agripino de Castro Júnior, do Programa de Mestrado e Doutorado em Ciência Jurídica da Univali.

2 Advogado, Master of Laws (LL.M.) e Doctor of Philosophy (Ph.D.) em Direito Marítimo Internacional (IMO International Maritime Law Institute - IMLI, Malta). Senior Lecturer, IMO International Maritime Law Institute - IMLI, Malta e pesquisador Visitante Estrangeiro, com apoio da Capes, no programa de Mestrado e Doutorado em Ciência Jurídica da Univali (Itajaí/SC). Autor do livro: Limitation of Liability in International Maritime Conventions: The Relationship between Global Limitation Conventions and Particular Liability Regimes. London / New York: Routledge, 2011, 412 p.

3 Advogada, Mestranda em Ciência Jurídica - Universidade do Vale do Itajaí. Bacharel em direito - Universidade do Vale do Itajaí (2009/02). Pós-Graduada em Direito Previdenciário - HGA Educação Continuada. Pós-Graduada em Direito do Trabalho - Associação dos Magistrados do Trabalho da 12a Região. Pós-Graduada em Formação para o Magistério Superior - Universidade do Vale do Itajaí. Autora do livro: Teoria Geral do Direito Internacional Previdenciário. CV: http://lattes.cnpq.br/8776359946756802 
Sea, 2002. The aim of the article is firstly, to offer some general observations on civil liability and, in particular, the way the subject is treated in relation to the carriage of passengers by sea. Following these general remarks, it gives a brief overview of the international treaties, examining the concept of the term international treaty, the steps required for this treaty to become enforceable, and the way in which it will be incorporated into domestic law. The article then examines the interpretation of the national courts on this issue. The second part of the article includes a discussion on the Athens Convention 2002, mentioning the countries that have already acceded to it, as well as the content and peculiarities of this agreement. The article follows the deductive method, and the techniques of referent, categories and operational concepts, as well as a review of the international literature on the subject.

KEYWORDS: Athens Convention 2002. Limitation of Liability. Carriage by Sea.

\section{RESUMEN}

Este artículo trata de la limitación de la responsabilidad civil relativa al transporte de pasajeros y sus equipajes por vía marítima a través del estudio de la Convención de Atenas Relativa al Transporte de Pasajeros y sus Equipajes por Mar de 2002 (Convención de Atenas 2002). La intención es esbozar algunas consideraciones generales, inicialmente acerca de la responsabilidad civil, reflexionando sobre la forma en que el tema es tratado en relación al transporte de pasajeros por vía marítima. A continuación se analiza el concepto de tratado internacional, las fases necesarias para que pueda adquirir ejecutoriedad y la forma en la que será recibido en el ordenamiento jurídico interno. A seguir, se intentó conocer la interpretación de los tribunales nacionales sobre el tema. En la segunda parte del artículo se investigó la Convención de Atenas 2002, informando cuáles eran los países que ya la habían adoptado, así como el contenido y las peculiaridades listadas en este acuerdo. Se adoptó el método inductivo y las técnicas del referente, categorías y conceptos operacionales, además de investigación de fuentes bibliográficas.

PALABRAS ClAVE: Convención de Atenas 2002. Limitación de la Responsabilidad Civil. Transporte Marítimo.

\section{INTRODUÇÃO}

O presente artigo tem como objeto o estudo da limitação da responsabilidade civil relativa ao transporte de passageiros e às suas bagagens por via marítima: Convenção de Atenas Relativa ao Transporte de Passageiros e suas Bagagens por Via Marítima de 2002 (Convenção de Atenas 2002).

A Convenção de Atenas Relativa ao Transporte de Passageiros e às suas Bagagens por Via Marítima (Convenção de Atenas), apesar de existir há um longo período (origem em 1974), jamais chegou a ser assinada e muito menos ratificada pelo Brasil, fazendo assim com que seja aplicado para os casos do ordenamento jurídico brasileiro apenas as regras estabelecidas no Código Civil e no Código de Defesa do Consumidor.

Constitui-se como objetivo geral deste trabalho investigar a limitação da responsabilidade civil relativa ao transporte de passageiro e suas bagagens por via marítima e as implicações da Convenção de Atenas 2002, buscando saber como a mesma se procede, quais os países que abrangem e as suas consequências jurídicas.

A relevância da pesquisa decorre da atualidade do tema e da segurança jurídica que a convenção poderá gerar no ordenamento jurídico pátrio e nos demais Estados.

Buscou-se analisar, no primeiro momento, o significado da limitação da responsabilidade civil, analisando a forma com que o tema é tratado em relação ao transporte marítimo de passageiros. Na sequência, intenta-se demonstrar o conceito do termo tratado internacional, as fases necessárias 
para que ele possa vir a adquirir executoriedade e a forma com que ele será recepcionado no ordenamento jurídico interno. Ato contínuo, buscou-se conhecer a interpretação dos tribunais nacionais sobre o tema. Dando continuidade à matéria, na segunda parte, investiga-se a Convenção de Atenas 2002, informando os países que já a adotaram, bem como o conteúdo e as peculiaridades do citado acordo.

O presente artigo se encerra com a conclusão, na qual são apresentados pontos conclusivos destacados. Assim, espera-se alcançar o intuito que motivou preferência por este estudo, qual seja, a aplicação dos conhecimentos e a estimulação à continuidade das pesquisas sobre a limitação da responsabilidade civil no Direito Marítimo brasileiro.

\section{CONSIDERAÇÕES GERAIS}

Antes de adentrar ao tema principal deste artigo, Convenção de Atenas 2002, é importante tecer alguns breves esclarecimentos acerca da responsabilidade civil, tratados internacionais e atual jurisprudência brasileira sobre a matéria.

\section{RESPONSABILIDADE CIVIL}

A responsabilidade civil no ordenamento jurídico brasileiro é a obrigação de se reparar um prejuízo em virtude de algum dano ocorrido. Assim, a pessoa prejudicada pode buscar, legalmente, perante o agente que cometeu o dano, sendo ele ainda o responsável por pessoa ou coisa que dele dependam, a reparação do prejuízo sofrido.

A responsabilidade civil está prevista no art. 927 do Código Civil ${ }^{4}$, que informa:

Art. 927. Aquele que, por ato ilícito (arts. 186 e 187), causar dano a outrem, fica obrigado a repará-lo.

Parágrafo único. Haverá obrigação de reparar o dano, independentemente de culpa, nos casos especificados em lei, ou quando a atividade normalmente desenvolvida pelo autor do dano implicar, por sua natureza, risco para os direitos de outrem.

Maria Helena Diniz ${ }^{5}$ assevera que a "Responsabilidade civil é a aplicação de medidas que obriguem uma pessoa a reparar o dano moral ou material causado a terceiros, em razão de ato por ele mesmo praticado, por pessoa por quem responde, por alguma coisa a ela pertencente ou de simples imposição legal".

O direito de limitação da responsabilidade é um conceito de suma importância no Direito Marítimo Internacional ${ }^{6}$, que é regulado por várias convenções internacionais sobre o assunto. Também o transporte de passageiros por via marítima é regulada por vários convênios internacionais importantes. Infelizmente, na área de limitação de responsabilidade o Brasil é parte de um acordo, em 1924, que agora está obsoleto, e no campo do transporte de passageiros por via marítima o Brasil não faz parte de nenhuma das convenções adotadas, deixando assim que a responsabilidade seja regulada pelos dispositivos do Código Civil.

De acordo com o Código Civil, a responsabilidade civil, no transporte de passageiros marítimo, é baseada nas teorias contratual e objetiva, independentemente de culpa, sendo que há a inversão do ônus da prova e fica o transportador, causador do dano, com a incumbência de demonstrar que não agiu com culpa.

4 BRASIL. Código Civil. Disponível em: <http://www.planalto.gov.br/ccivil_03/leis/2002/ L10406compilada.htm>. Acesso em: 17 ago. 2012.

5 DINIZ, Maria Helena. Curso de direito civil: Responsabilidade Civil. 18. ed. São Paulo: Saraiva, 2004. v. 7, p. 57.

6 O citado tema é objeto da pesquisa de cooperação internacional realizada pelo Programa de PósGraduação em Ciência Jurídica da UNIVALI e o International Maritime Law Institute, IMLI, IMO, Malta, com apoio da CAPES e coordenada pelos Professores Doutor Osvaldo Agripino de Castro Júnior e Doutor Norman A. Martínez Gutiérrez. A escolha do tema da referida pesquisa se deu com fundamento nas poucas doutrina e publicações sobre a ratificação dos tratados internacionais que regulam o tema. 
Segundo Pualo Henrique Cremoneze ${ }^{7}$, a responsabilidade civil, no transporte de passageiros por vía marítima, é baseada na teoria objetiva imprópria, que significa que a culpa do transportador é sempre presumida.

Verificando esta situação, observamos que a responsabilidade civil contratual visa proteger o princípio da norma pacta sunt servanda, pois significa que os acordos devem ser cumpridos fielmente, segundo o que foi pactuado entre as partes. Já a teoria objetiva se baseia no fato de que certas atividades profissionais possuem em si só um risco, fazendo assim com que o responsável por esta atividade tenha o dever de indenizar.

Isto significa que a responsabilidade civil contratual visa proteger o princípio da norma pacta suntservana que significa pactos são cumpridos. Já a teoria objetiva se baseia no fato de que certas atividades profissionais possuem em si só um risco, fazendo assim com que o responsável por esta atividade tenha o dever de indenizar.

Por sua vez, Osvaldo Agripino de Castro Júnior ${ }^{8}$ esclarece que não é o passageiro ou o dono da mercadoria quem deve provar a culpa do transportador, mas sim o transportador, pois esse é quem deve provar a exoneração da sua responsabilidade por meio da ausência de culpa.

Todavia o transportador poderá demonstrar alguma excludente de ausência da responsabilidade civil, que podem ser: 1) ausência de nexo causal; 2) culpa exclusiva da vítima; 3) caso fortuito; 4) força maior. Ademais, quando a responsabilidade for em decorrência de culpa concorrente, será estabelecida uma média de culpa de cada parte e assim será reduzida a responsabilidade.

Segundo Carla Gilbertoni: " No Direito Marítimo, em Geral, a responsabilidade decorre do inadimplemento contratual ou deriva de acontecimentos aleatórios em decorrência de danos por acidentes ou fatos da navegação".

São várias as obrigações assumidas pelo transportador por força do contrato de transporte, antes, durante e depois da viagem. Se descumprir qualquer delas por fato a si imputável, responde por perdas e danos ${ }^{10}$.

Assim, é importante trazer o disposto na Súmula 187 da STF:

Súmula 187: A responsabilidade contratual do transportador, pelo acidente com o passageiro, não é elidida por culpa de terceiro, contra o qual tem ação regressiva.

Referido dispositivo legal veio unificar o posicionamento da jurisprudência que era unânime em informar que é responsável o transportador por acidente com passageiro, mesmo que este ocorra por culpa, sendo porém permitida a ação de regresso entre o transportador e este terceiro causador do dano.

Outro ponto que deve ser esclarecido é o das chamadas cláusulas contratuais de não indenização ou de irresponsabilidades.

Referidas cláusulas contratuais visam retirar toda e qualquer responsabilidade do transportador. Todavia o ordenamento jurídico brasileiro não admite a viabilidade deste tipo de termo, fazendo assim com que ela seja plenamente inoperante, conforme dispõe a Súmula 161 do STF:

Súmula 161: Em contrato de transporte, é inoperante a cláusula de não indenizar.

Porém, quando tratamos de cláusula de limitação de responsabilidade, essa tem sido admitida no Brasil, uma vez que não visam à exoneração da sua responsabilidade.

O Superior Tribunal de Justiça já decidiu que "é válida a cláusula limitativa de responsabilidade de indenizar inserta em contrato de transporte marítimo" (REsp 153.787/SP, 4a Turma, Rel. Min. Barros Monteiro).

7 CREMONEZE, Paulo Henrique. Prática de direito marítimo: o contrato de transporte marítimo e a responsabilidade civil do transportador, p. 89.

8 CASTRO JÚNIOR, Osvaldo Agripino de (Org.). Direito marítimo: temas atuais. Belo Horizonte: Fórum, 2012, p. 72.

9 GILBERTONI, Carla Adrina C. Teoria e prática do direito marítimo.

10 SANTOS, Herez. Introdução ao direito marítimo. Parte integrante da Edição no 24. Disponível em: <http://www.boletimjuridico.com.br/doutrina/texto.asp?id=44>. Acesso em: 17 ago. 2012. 
Ocorre que, quando é configurada a culpa grave, esta cláusula de limitação acaba perdendo a validade, fazendo assim com que ocorra a obrigação de indenizar integral, ou seja, sem limitação de valor.

Além disso, ao tratarmos da responsabilidade no transporte marítimo de passageiros, por não haver uma legislação específica acerca do tema, tem-se aplicado o Código de Defesa do Consumidor, uma vez que o transporte de passageiro é, sem dúvida alguma, uma relação de consumo.

O Brasil não possui, ainda, um regimento jurídico específico que regula a responsabilidade civil acerca do transporte marítimo de passageiros. Muito pelo contrário, o ordenamento jurídico interno possui pouca legislação que trata especificamente do Direito Marítimo.

Em contrapartida, há inúmeros acordos e convenções internacionais acerca do tema, porém o Estado brasileiro ainda não os ratificou.

Estes acordos, dentre os quais a Convenção Atenas 2002, trazem segurança jurídica para as partes, pois chegam até mesmo a estabelecer fundamentos legais para a imposição de responsabilidade e determinam uma limitação para fins de responsabilidade civil.

Assim, as convenções internacionais e, principalmente, a Convenção de Atenas 2002, buscam estabelecer a responsabilidade do transportador por danos aos passageiros e, em alguns casos, até mesmo faz com que ele não seja responsabilizado. Por outro lado, estes convênios incluem limites à responsabilidade do transportador.

\section{TRATADOS INTERNACIONAIS}

Para que se possa compreender o funcionamento de uma convenção internacional, é necessário realizar um breve esclarecimento sobre o seu conceito, a sua implementação e o seu status constitucional.

Os tratados vigoram como lei entre as partes pactuantes e, dentre as fontes do Direito Internacional, o Tratado destaca-se como o mais importante, por versar sobre os assuntos de maiores interesses e ser bastante seguro quanto à precisão de seu conteúdo. Na esfera internacional, o tratado e a convenção são terminologias sinônimas ${ }^{11}$. Todavia os costumes devem, igualmente, ser respeitados, uma vez que possuem extrema relevância.

A Convenção de Viena ${ }^{12}$, em seu art. 20, 1, "a", traz o seguinte conceito de tratado: "acordo internacional concluído por escrito entre Estados e regido pelo Direito Internacional, quer conste de um instrumento único, quer de dois ou mais instrumentos conexos, qualquer que seja sua denominação específica".

Para Rezek ${ }^{13}$, "tratado é todo acordo formal concluído entre sujeitos de direito internacional público, e destinado a produzir efeitos jurídicos".

Vale destacar que, anteriormente, o Supremo Tribunal Federal adotava o entendimento de que todo e qualquer tratado internacional, independentemente de seu conteúdo, tinha a natureza jurídica de lei ordinária. Tal posicionamento era por força do art. 102, III, b, da Constituição Brasileira ${ }^{14}$, que informa in verbis:

Art. 102. Compete ao Supremo Tribunal Federal, precipuamente, a guarda da Constituição, cabendo-Ihe:

(...)

III - julgar, mediante recurso extraordinário, as causas decididas em única ou última instância, quando a decisão recorrida:

11 GAMA, Ricardo Rodrigues. Introdução ao direito internacional. São Paulo: Belo Horizonte, 2006. p.99.

12 Convenção de Viena sobre o Direito dos Tratados. Disponível em: <http://www.planalto. gov. br/ccivil_03/_Ato2007-2010/2009/Decreto/D7030.htm>. Acesso em: 17 ago. 2012.

13 REZEK, José Francisco. Direito internacional público: curso elementar. 5. ed. São Paulo: Saraiva, 1995. p. 14.

14 BRASIL. Constituição da República Federativa do Brasil, de 5 de outubro de 1988. Disponível em: <http://www.planalto.gov.br/ccivil_03/constituicao/constitui\%C3\%A7ao.htm>. Acesso em: 17 ago. 2012. 
$(\ldots)$

b) declarar a inconstitucionalidade de tratado ou lei federal;

Todavia a Emenda Constitucional no 45, de 8 de dezembro de 2004, acrescentou um terceiro parágrafo ao artigo $5^{\circ}$, sendo que os tratados e as convenções internacionais que visam à matéria referente a direitos humanos, se aprovados em cada Casa do Congresso Nacional, em dois turnos, por três quintos dos votos dos respectivos membros, serão equivalentes às emendas constitucionais.

Para que um acordo internacional seja incorporado ao ordenamento jurídico interno, e com isso venha adquirir executoriedade, ele precisa cumprir obrigatoriamente três fases. Moraes as ensina ${ }^{15}$ :

$1^{\text {a }}$ fase: compete privativamente ao Presidente da República celebrar todos os tratados, convenções e atos internacionais (CF, art. 84, VIII);

$2^{a}$ fase: é de competência exclusiva do Congresso Nacional resolver definitivamente sobre tratados, acordos ou atos internacionais que acarretem encargos ou compromissos gravosos ao patrimônio nacional ( $\mathrm{CF}$, art. 49, I). A deliberação do Parlamento será realizada através da aprovação de um decreto legislativo, devidamente promulgado pelo Presidente do Senado Federal e publicado;

$3^{a}$ fase: edição de um decreto do Presidente da República, promulgando o ato ou tratado internacional devidamente ratificado pelo Congresso Nacional. É nesse momento que adquire executoriedade interna a norma inserida pelo ato ou tratado internacional, podendo, inclusive, ser objeto de ação direta de inconstitucionalidade.

No caso em tela, ao analisarmos a Convenção de Atenas 2002, observamos que se trata de uma questão meramente acerca de responsabilidade civil do transportador. Dessa forma, pode-se definir que esta convenção, caso entre em vigor no ordenamento jurídico interno brasileiro, teria um status de lei ordinária e se situaria no nível intermediário, ao lado dos atos normativos primários.

\section{JURISPRUDÊNCIA}

Para entender-se o posicionamento do Poder Judiciário brasileiro acerca da matéria, é relevante uma breve pesquisa jurisprudencial. Assim serão demonstrados três casos concretos relacionados à indenização no transporte marítimo de passageiros, todos eles relevantes para o debate investigado neste artigo, quais sejam:

INDENIZAÇÃO - Danos materiais e morais - Extravio de bagagem - Transporte marítimo de passageiros - Responsabilidade da transportadora bem demonstrada - Valor dos danos tanto morais como materiais bem avaliado e arbitrado na sentença - Procedência parcial bem decretada Apelação da ré provida em parte apenas para redistribuir os ônus da sucumbência, não providos os demais recursos. (239677020098260451 SP, Relator: Ulisses do Valle Ramos, Data de Julgamento: 24/11/2010, 13a Câmara de Direito Privado, Data de Publicação: 09/12/2010)

ADMINISTRATIVO. RESPONSABILIDADE CIVIL. NAUFRÁGIO DA EMBARCAÇÃO "BATEAU MOUCHE IV". DESCONSIDERAÇÃO DA PERSONALIDADE JURÍDICA. RESPONSABILIDADE SOLIDÁRIA DOS RÉUS. 1. Justifica-se tratamento mais severo na seara das relações de consumo, quando do enfrentamento da retirada do véu protetor das pessoas jurídicas, com a aplicação da "disregard doctrine", mormente diante das constantes práticas abusivas, e desenfreada busca do "lucro a qualquer preço", pelas sociedades empresárias, em detrimento dos consumidores, o que já era possível antes mesmo da vigência do Código Consumerista. 2. Salta aos olhos que a sociedade empresária em comento, por intermédio dos seus sócios, exerceram abusivamente o negócio de transporte marítimo de passageiros, sem qualquer contrapartida em seu patrimônio resultando na perda de 55 vidas. 3. Honorários advocatícios incidentes sobre a condenação, assim consideradas as verbas vencidas e doze das prestações vincendas. 4. Para fins de fixação de juros de mora, há que diferenciar o ilícito contratual do extracontratual que incidirão em 0,5\% (meio por cento) ao mês, a partir da citação, durante a vigência do revogado CC de 1916 e, após, passam a ser computados no percentual de $1 \%$ (um por cento). CC5. Remessa oficial e recursos de apelação parcialmente providos. (199351010137789 RJ 1993.51.01.013778-9, Relator: Desembargadora Federal SALETE MACCALOZ, Data de Julgamento: 02/06/2010, SÉTIMA TURMA ESPECIALIZADA, Data de Publicação: E-DJF2R - Data: 21/06/2010 - Página: 395/396).

15 MORAES, Alexandre de. Direito constitucional. 22. ed. São Paulo: Atlas, 2004. p. 590. 
"INDENIZAÇÃO - Danos materiais e morais - Extravio de bagagem - Transporte marítimo de passageiros - Responsabilidade da transportadora bem demonstrada - Valor dos danos tanto morais como materiais bem avaliado e arbitrado na sentença - Procedência parcial bem decretada - Apelação da ré provida em parte apenas para redistribuir os ônus da sucumbência, não providos os demais recursos. (990104345200 SP, Relator: Ulisses do Valle Ramos, Data de Julgamento: 24/11/2010, 13a Câmara de Direito Privado, Data de Publicação: 09/12/2010).

Após uma introdução acerca de responsabilidade civil, dos tratados internacionais e da análise da jurisprudência atual, é necessário, para alcançar o objetivo deste artigo, estudar especificamente a Convenção de Atenas 2002, o que será feito no próximo capítulo.

\section{CONVENÇÃO DE ATENAS $2002^{16}$}

A Convenção de Atenas Relativa ao Transporte de Passageiros e às suas Bagagens por Via Marítima foi estabelecida visando estabelecer a responsabilidade e reconhecer o direito de limitação da responsabilidade civil do transportador de passageiros em embarcações de longo curso no caso de perdas e danos sofridos por passageiros e suas bagagens.

Referida convenção foi adotada em 13 de dezembro de 1974, e a sua entrada em vigor internacionalmente ocorreu apenas em 28 de abril de 1987, e até os dias atuais foi adotada por 34 (trinta e quatro) países, sendo eles: Albânia, Argentina, Bahamas, Barbados, Bélgica, Belize, China, Croácia, Dominica, Egito, Espanha, Estônia, Rússia, Geórgia, Grécia, Guiana, Guiné Equatorial, Iémen, Ilhas Marshall, Irlanda, Jordânia, Letônia, Libéria, Luxemburgo, Malavi, Nigéria, Polônia, Reino Unido, São Cristóvão e Nevis, Sérvia, Suíça, Tonga, Ucrânia, Vanuatu ${ }^{17}$.

Uma vez que esta convenção trata de responsabilidade civil, e desta forma dispõe acerca do valor das indenizações, em 2002 realizou-se um novo protocolo, no qual foram revistos e atualizados os valores estabelecidos, bem como foram criadas novas cláusulas para as indenizações.

O protocolo de 2002 teve a adoção em 01 de dezembro de 2002, porém não se encontra, ainda, em vigor, sendo que a sua efetivação ocorrerá 12 (doze) meses após a data em que, no mínimo, 10 (dez) países membros tenham assinado esta ratificação, aceitação ou aprovação sem qualquer reserva, ou tenham depositado instrumento desta adesão.

Porém, para que os Estados participantes da Convenção de Atenas possam aderir ao novo protocolo (2002), devem denunciar, ou seja, renunciar, a convenção inicial de 1974, e os protocolos de 1976 e 1990, uma vez que os valores, as indenizações e as demais responsabilidades seriam derrogados.

Até 31 de julho de 2012 apenas 8 países já ratificaram o novo protocolo de 2002, número este inferior do necessário para a entrada em vigor, são eles: Albânia, Belize, Dinamarca, Letônia, Palau, São Cristóvão e Nevis, Sérvia, Síria ${ }^{18}$.

Ocorre que, além desses países, a União Europeia também já ratificou este protocolo, porém é necessária a tramitação interna para que os países que delam fazem parte passem a aderir esta convenção.

Como se pode observar, o Brasil não é parte contratante da Convenção de Atenas, muito menos dos protocolos de 1976 e 1990, sendo que sequer chegou a assinar o referido acordo. No mesmo sentido, até o momento, o país não manifestou interesse na adesão ao Protocolo de 2002.

Para que haja uma explicação mais clara e correta acerca do tema, tratar-se-á cada ponto do novo protocolo em tópicos, iniciando sobre definições e, posteriormente, da responsabilidade do transportador; seguro compulsório; objetos de valores; limite de responsabilidade por morte ou

16 Para uma discussão detalhada do Convenio de Atenas e o Convenio de Atenas 2002 consultar MARTíNEZ GUTIÉRREZ, Norman A. Limitation of Liability in International Maritime Conventions: The Relationship between Global Limitation Conventions and Particular Liability Regimes. London / New York: Routledge, 2011, pp. 113-144.

17 Status of conventions as at 31 july 2012. Disponível em: <http://www.imo.org/About/ Conventions/StatusOfConventions/Pages/Default.aspx>. Acesso em: 17 ago. 2012.

18 Status of conventions as at 31 july 2012. Disponível em: <http://www.imo.org/About/ Conventions/StatusOfConventions/Pages/Default.aspx>. Acesso em: 17 ago. 2012. 
lesão corporal; limite de responsabilidade por perda ou dano a bagagens ou a veículos; notificação da perda da bagagem; prazo limite para a propositura de ação judicial; jurisdição competente; outras ponderações e jurisprudências.

É importante esclarecer que, apesar de ter sido originada por um protocolo de 2002, pode-se referir a este acordo como Convenção de Atenas Relativa ao Transporte de Passageiros e suas Bagagens por Via Marítima.

É importante esclarecer que, o Convenio de Atenas e o Protocolo de 2002 devem ser lidos e interpretados juntos, como um só instrumento, aos quais se pode referir como Convenção de Atenas Relativa ao Transporte de Passageiros e suas Bagagens por Via Marítima de 2002.

\section{DEFINIÇÕES}

Antes de adentrar ao conteúdo específico da Convenção de Atenas 2002, é importante conhecer o significado de alguns termos e expressões comumente usadas, que igualmente estão estabelecidas na convenção, em seu artigo $1^{19}$ :

a) Navio: significa apenas uma embarcação marítima, excluindo veículos com colchão de ar;

b) Transportador: significa aquele por quem ou em nome de quem foi celebrado um contrato, independente do transporte ser de fato feito por tal pessoa ou por um transportador executante;

c) Transportador executante: não significa o transportador propriamente dito, mas o armador, afretador ou o operador do navio que realiza de fato todo ou parte do transporte;

d) Passageiro: significa qualquer pessoa transportada em um navio sob um contrato de transporte ou, com o consentimento do transportador, esteja acompanhando um veículo ou animais vivos cobertos por um contrato de transporte de mercadorias não reguladas por esta Convenção;

e) Bagagem: significa qualquer artigo ou veículo transportado pelo transportador sob um contrato de transporte, excluindo: 1) artigos e veículos transportados por um afretador, ou outro contrato cobrindo principalmente o transporte de mercadorias, e 2) animais vivos;

f) Bagagem de cabine: significa a bagagem que o passageiro tenha em sua cabine ou da qual esteja de posse ou que esteja sob sua guarda ou controle.

g) Contrato de transporte: significa um contrato feito por ou em nome de um transportador para o transporte por via marítima de um passageiro ou de um passageiro e sua bagagem.

h) Perda ou dano à bagagem: inclui prejuízo patrimonial resultante da bagagem não ter sido devolvida ao passageiro dentro de um período de tempo razoável após a chegada do navio no qual a bagagem tenha sido, ou deveria ter sido, transportada, mas não inclui atrasos resultantes de litígios trabalhistas (ex: greve).

i) Litígios trabalhistas (ex: greve).

Após conhecer alguns significados importantes para a matéria, passar-se-á a abordar a essência da Convenção de Atenas 2002.

\section{ÂMBITO DE APLICAÇÃO}

O artigo $2^{\circ}$ da Convenção de Atenas de $2002^{20}$ estabelece que a sua aplicação ocorrerá apenas nas seguintes hipóteses:

a) O navio estiver arvorando a bandeira, ou estiver registrado em um Estado Parte desta

19 CONVENÇÃO de Atenas Relativa ao Transporte de Passageiros e suas Bagagens por Via Marítima, 2002. Disponível em: <https://www.ccaimo.mar.mil.br/sites/default/files/Conv_ Consolidado_2002.pdf>. Acesso em: 17 ago. 2012.

20 CONVEnÇÃo de Atenas Relativa ao Transporte de Passageiros e suas Bagagens por Via Marítima, 2002. Disponível em: <https://www.ccaimo.mar.mil.br/sites/default/files/Conv_ Consolidado_2002.pdf>. Acesso em: 17 ago. 2012. 
Convenção, ou

b) O contrato de transporte tiver sido celebrado em um Estado Parte desta Convenção, ou

c) O local de partida ou de destino, de acordo com o contrato de transporte, estiver localizado em um Estado Parte desta Convenção.

\section{RESPONSABILIDADE DO TRANSPORTADOR}

O transportador será responsável tanto pelas perdas originadas por morte ou lesão corporal, quanto pelas bagagens de cabine ou não21.

Para os casos de morte ou lesão corporal a um passageiro causada por um incidente de navegação (afundamento, emborcamento, colisão, encalhe, explosão, incêndio ou defeito no navio), a responsabilidade do transportador é objetiva até uma quantidade de 250.000 unidades monetárias, que são os direitos especiais de saque, sendo que até agosto de 2012 corresponde a R\$761.200,00 por passageiro 22 . No entanto o transportador não é responsável se puder provar que a fatalidade se deu em função de ato ou omissão intencional de terceiros ou um ato de guerra, hostilidade, guerra civil, insurreição ou de um fenômeno de caráter excepcional, inevitável e irresistível ${ }^{23}$.

Caso os danos e/ou as perdas ultrapassem o limite estipulado, o transportador será responsável adicionalmente, salvo se provar que o incidente ocorreu sem que houvesse a sua falta ou negligência.

Ademais, para os casos em que não tenha ocorrido um incidente de navegação (afundamento, emborcamento, colisão, encalhe, explosão, incêndio ou defeito no navio), o transportador será responsável sempre que ele ou seus funcionários agirem com falta ou negligência no desempenho de suas funções.

Quando se tratar de perda ou danos à bagagem das cabines, o transportador será responsável sempre que este incidente tiver sido gerado em virtude da falta ou da negligência tanto do transportador quanto de seus funcionários no desempenho de suas funções. Esta falta ou negligência será presumida sempre que os prejuízos tiverem ocorrido em razão de um incidente da navegação ${ }^{24}$.

Já para a bagagem que não seja a de cabine, a perda ou o dano será sempre de responsabilidade do transportador, a menos que ele prove que o incidente causador da perda ocorreu sem qualquer falta ou negligência.

É importante destacar que o ônus da prova para as perdas provenientes de qualquer incidente ocorrido durante o transporte será do Reclamante.

Mesmo que o transporte tenha sido efetivado por um "transportador executante" o "transportador" não deixará de ser responsável pela lesão ou morte, e perda ou dano de bagagem²5.

Enquanto o "transportador executante" só é responsável por danos ou prejuízos que ocorrem durante o transporte que o execute, o "transportador" permanecerá responsável por danos ou prejuízos que ocorrem durante o transporte, porque sempre será responsável por qualquer ato ou

21 Para uma discussão detalhada acerca da responsabilidade do transportador consultar MARTÍNEZ GUTIÉRREZ, Norman A. Limitation of Liability in International Maritime Conventions: The Relationship between Global Limitation Conventions and Particular Liability Regimes. London / New York: Routledge, 2011, pp.134-138.

22 COTAÇÃo de moedas. Disponível em: <http://www.correios.com.br/internacional/cfm/ cotacao_moedas.cfm>. Acesso em: 17 ago. 2012. (DES - Direito Especial de Saque R\$ 3,0448 [250.000 x 3,0448 $=R \$ 761.200,00])$.

23 ARTIGo 3, ponto 1, (a), da Convenção de Atenas Relativa ao Transporte de Passageiros e suas Bagagens por Via Marítima, 2002. Disponível em: <https://www.ccaimo.mar.mil.br/ sites/ default/files/Conv_Consolidado_2002.pdf>. Acesso em: 17 ago. 2012.

24 ARTigo 3, pontos 2 e 3, da Convenção de Atenas Relativa ao Transporte de Passageiros e suas Bagagens por Via Marítima, 2002. Disponível em: <https://www. ccaimo.mar.mil.br/sites/ default/files/Conv_Consolidado_2002.pdf>. Acesso em: 17 ago. 2012.

25 ARTIgo 4 da Convenção de Atenas Relativa ao Transporte de Passageiros e suas Bagagens por Via Marítima, 2002. Disponível em: <https://www.ccaimo.mar.mil.br/sites/ default/files/ Conv_Consolidado_2002.pdf>. Acesso em: 17 ago. 2012. 
omissão do "transportador executante", sendo que sempre que ambos forem considerados culpados, esta responsabilidade será conjunta e solidária.

Ademais, esta Convenção não impede que o transportador responsabilizado ajuíze uma ação de regresso contra terceiros.

\section{OBJETOS DE VALORES}

Quando se tratar de uma bagagem contendo dinheiro, títulos mobiliários negociáveis, ouro, prata, joias, obras de arte, etc., o transportador não deverá ser responsável pela perda ou dano, salvo quando tais objetos tenham sido depositados com o transportador, visando guardar tais valores, por exemplo: quando é depositado em um cofre do navio, onde o responsável é o transportador, e não o cofre particular que pode haver em cada cabine ${ }^{26}$.

Caso o transportador se enquadre nesta exceção, esta Convenção prevê uma limitação para a sua responsabilidade, que não deverá extrapolar a quantia de 3.375 unidades monetárias por passageiro e por transporte, ou seja, $\mathrm{R} \$ 10.276,20$, atualizado até outubro de $2012^{27}$.

Esta limitação somente não será aplicada caso o passageiro e o transportador tenham acordado, expressamente, e por escrito um limite maior de responsabilidade.

\section{LIMITE DE RESPONSABILIDADE POR MORTE OU LESÃO CORPORAL}

A Convenção de Atenas 2002 estipulou que, em nenhuma hipótese, nem mesmo em decorrência de uma decisão judicial, a responsabilidade do transportador em face de morte ou lesão corporal de um passageiro pode ultrapassar 400.000 unidades monetárias por passageiro em cada ocasião distinta, ou seja, $R \$ 1.217 .092,00$, atualizado até agosto de $2012^{28}$.

Se houver uma condenação judicial, para que seja pago alguma renda periódica, o valor pago e somado jamais poderá ultrapassar o limite acima informado.

Todavia, caso um Estado Parte desta convenção deseje fixar algum outro limite de responsabilidade, ele poderá, desde que este limite nacional de responsabilidade não seja inferior ao estabelecido pelo convênio.

O Estado Parte que utilizar essa opção deverá informar ao Secretário Geral da Convenção o limite de responsabilidade adotado ou o fato de não haver limites.

\section{LIMITE DE RESPONSABILIDADE POR PERDA OU DANO A BAGAGENS OU A VEÍCULOS}

Quanto se trata da perda ou dano a uma bagagem de cabine, a Convenção de Atenas 2002 prevê um limite de responsabilidade que não deverá exceder, em nenhum caso, 2.250 unidades monetárias por passageiro e por transporte, ou seja, $\mathrm{R} \$ 6.850,80$, atualizado até agosto de $2012^{29}$.

26 ARTIGo 5 da Convenção de Atenas Relativa ao Transporte de Passageiros e suas Bagagens por Via Marítima, 2002. Disponível em: <https://www.ccaimo.mar.mil.br/sites/ default/files/Conv_ Consolidado_2002.pdf>. Acesso em: 17 ago. 2012. Para uma discussão detalhada acerca da responsabilidade do transportador por objetos de valor consultar MARTÍNEZ GUTIÉRREZ, Norman A. Limitation of Liability in International Maritime Conventions: The Relationship between Global Limitation Conventions and Particular Liability Regimes. London / New York: Routledge, 2011, pp. 121-122.

27 COTAÇÃO de moedas. Disponível em: <http://www.correios.com.br/internacional/cfm/ cotacao_moedas.cfm>. Acesso em: 17 ago. 2012. (DES - Direito Especial de Saque R\$3,0448 [3.375 x 3,0448 = R\$ 10.276,20]).

28 COTAÇÃo de moedas. Disponível em: <http://www.correios.com.br/internacional/cfm/ cotacao_ moedas.cfm>. Acesso em: 17 ago. 2012. (DES - Direito Especial de Saque R\$ 3,0448 [400.000 x $3,0448=\mathrm{R} \$ 1.217 .092,00])$. Para uma discussão detalhada acerca do limite da responsabilidade do transportador consultar MARTÍNEZ GUTIÉRREZ, Norman A. Limitation of Liability in International Maritime Conventions: The Relationship between Global Limitation Conventions and Particular Liability Regimes. London / New York: Routledge, 2011, pp.123-126, 128 e 138-140.

29 COTAÇÃo de moedas. Disponível em: <http://www.correios.com.br/internacional/cfm/ cotacao_moedas.cfm>. 
Já para os casos em que ocorre a perda ou o dano ao veículo, inclusive toda a bagagem transportada em cima ou no interior do veículo, a responsabilidade do transportador não excederá 12.700 unidades monetárias por veículo e por transporte, ou seja, $\mathrm{R} \$ 38.668,96$, atualizado até agosto de $2012^{30}$.

Novamente esta limitação somente não será aplicada apenas caso o passageiro e o transportador tenham acordado expressamente e, por escrito, um limite de responsabilidade mais elevado.

\section{SEGURO COMPULSÓRIO}

A Convenção de 2002 passou a exigir que todo navio que esteja autorizado para transportar mais de 12 passageiros deverá manter um seguro ou outra garantia financeira, tal como a garantia de um banco ou instituição financeira semelhante que cubra a responsabilidade objetiva no âmbito da Convenção no que diz respeito à morte ou à lesão corporal dos passageiros. ${ }^{31}$

O limite do seguro obrigatório ou outra garantia financeira não deve ser inferior a 250.000 unidades monetárias por passageiro em cada ocasião distinta, ou seja, R\$761.200,00, atualizado até agosto de $2012^{32}$.

Para cada navio deverá ser emitido um certificado atestando que um seguro ou outra garantia financeira está em vigor, sendo que esse certificado deverá ser mantido a bordo e uma cópia deverá ser entregue para as autoridades que mantêm o registro do navio.

Para requerer a indenização, no montante coberto pelo seguro, o pedido pode ser feito diretamente com o segurador. Para valores acima do assegurado, deve-se entrar judicialmente para pleitear esta diferença a cargo do transportador.

\section{NOTIFICAÇÃO DA PERDA DA BAGAGEM}

Sempre que o passageiro tiver algum problema com a sua bagagem, ele deverá notificar o transportador ou o seu agente por escrito.

Para os danos aparentes à bagagem, esta notificação deverá ocorrer da seguinte forma, de acordo com o artigo 15.1 , da referida convenção ${ }^{33}$ :

a) Bagagem de Cabine: antes ou na hora do desembarque do passageiro;

b) Demais bagagens: antes ou na hora de sua entrega;

Quanto aos danos às bagagens que não sejam aparentes, ou ainda no caso de perda de bagagem, o passageiro deverá efetuar a notificação dentro de 15 dias, a partir da data de desembarque ou entrega, ou a partir da hora em que tal entrega deveria ter ocorrido.

Caso o passageiro não cumpra essa notificação, presume-se, a menos que seja provado o contrário, que ele recebeu a sua bagagem intacta.

Acesso em: 17 ago. 2012. (DES - Direito Especial de Saque R\$3,0448 [2.250 x 3,0448 = R\$ 6.850,80]).

30 COTAÇÃo de moedas. Disponível em: <http://www.correios.com.br/internacional/cfm/ cotacao_moedas.cfm>. Acesso em: 17 ago. 2012. (DES - Direito Especial de Saque R\$3,0448 [12.700 x 3,0448= $\mathrm{R} \$ 38.668,96])$. Para uma discussão detalhada acerca do limite da responsabilidade do transportador consultar MARTÍNEZ GUTIÉRREZ, Norman A. Limitation of Liability in International Maritime Conventions: The Relationship between Global Limitation Conventions and Particular Liability Regimes. London / New York: Routledge, 2011, pp.123-126, 128 e 138-140.

31 Para uma discussão detalhada acerca do seguro compulsório consultar MARTÍNEZ GUTIÉRREZ, Norman A. Limitation of Liability in International Maritime Conventions: The Relationship between Global Limitation Conventions and Particular Liability Regimes. London / New York: Routledge, 2011, pp.134-138.

32 COTAÇÃo de moedas. Disponível em: <http://www.correios.com.br/internacional/cfm/ cotacao_ moedas.cfm>. Acesso em: 17 ago. 2012. (DES - Direito Especial de Saque R\$ 3,0448 [250.000 x $3,0448=R \$ 761.200,00])$.

33 CONVENÇÃo de Atenas Relativa ao Transporte de Passageiros e suas Bagagens por Via Marítima, 2002. Disponível em: <https://www.ccaimo.mar.mil.br/sites/default/files/Conv_ Consolidado_2002.pdf>. Acesso em: 17 ago. 2012. 
Esta notificação não precisa ocorrer, apenas, caso a condição da bagagem tenha, no momento de seu recebimento, sido sujeita à vistoria ou à inspeção conjunta.

\section{PRAZO LIMITE PARA A PROPOSITURA DE AÇÃO JUDICIAL}

A Convenção estabeleceu um prazo de prescrição de 2 (dois) anos para que seja proposta qualquer ação visando ao ressarcimento e/ou à indenização de danos provenientes de morte ou lesão corporal a um passageiro ou de perda ou dano à sua bagagem.

Esta prescrição deverá ser calculada da seguinte maneira, conforme dispõe o artigo $16.2^{34}$ :

a) no caso de lesão corporal, a partir da data do desembarque do passageiro;

b) no caso de morte ocorrida durante o transporte, a partir da data na qual o passageiro deveria ter desembarcado;

c) no caso de lesão corporal ocorrida durante o transporte e resultando na morte do passageiro após o desembarque, a partir da data da morte, desde que este período não seja superior a três anos a partir da data do desembarque;

d) no caso de perda ou dano à bagagem, a partir da data do desembarque ou a partir da data na qual o desembarque deveria ter ocorrido, o que for mais tarde.

Qualquer suspensão e interrupção dos limites descritos anteriormente serão regidas pela lei do Tribunal, que está acompanhando o caso. No entanto a Convenção prevê, no artigo 16.3, que nenhuma reclamação pode ser apresentada após o decurso de qualquer dos seguintes termos:

a) um período de cinco anos a partir da data de desembarque do passageiro ou da data em que o desembarque deveria ter ocorrido, o que mais tarde, ou se anterior;

b) um período de três anos a partir da data em que o requerente sabia ou poderia razoavelmente ter conhecimento da lesão, perda ou dano causados pelo incidente.

Sem prejuízo do disposto acima, de acordo com o artigo 16.4 da Convenção, os períodos acima poderão ser prorrogados por uma declaração por escrito do transportador ou por um acordo escrito entre as partes, após o incidente ter ocorrido.

\section{JURISDIÇÃO COMPETENTE}

O foro competente para a propositura de ações decorrentes de danos dispostos nesta convenção (morte ou lesão corporal, perda ou dano à bagagem) deverá ser aquele localizado em um Estado Parte da Convenção.

Caso não seja possível, será aplicada a seguinte ordem de competência ${ }^{35}$ :

a) Tribunal do Estado de residência permanente ou principal local de negócios do réu; ou

b) Tribunal do Estado de partida ou de destino, de acordo com o contrato de transporte; ou

c) Tribunal do Estado de domicílio ou residência permanente do reclamante, se o réu tiver um local de negócios nesse Estado e esteja sujeito a sua jurisdição, ou

d) Tribunal do Estado onde o contrato de transporte foi celebrado, se o réu tiver um local de negócios nesse Estado e esteja sujeito a sua jurisdição.

34 Convenção de Atenas Relativa ao Transporte de Passageiros e suas Bagagens por Via Marítima, 2002. Disponível em: <https://www.ccaimo.mar.mil.br/sites/default/files/Conv_Consolidado_2002. pdf>. Acesso em: 17 ago. 2012.

35 Artigo 17, ponto 1, da Convenção de Atenas Relativa ao Transporte de Passageiros e suas Bagagens por Via Marítima, 2002. Disponível em: <https://www.ccaimo.mar.mil.br/ sites/default/ files/Conv_Consolidado_2002.pdf>. Acesso em: 17 ago. 2012. 
Finalizando acerca da Convenção de Atenas 2002, é importante mencionar que sempre que o passageiro causar ou contribuir mediante negligência para que ocorra a sua morte ou lesão corporal, ou a perda ou o dano à sua bagagem, e o transportador conseguir provar essa situação, o tribunal que julgar o caso poderá exonerar o transportador de toda ou parte de sua responsabilidade, de acordo com as disposições da lei daquele tribunal.

Será nula e sem efeito toda e qualquer cláusula contratual que tenha a finalidade de eximir a responsabilidade de qualquer pessoa acerca de incidente que originou a morte ou a lesão corporal de um passageiro, ou a perda ou o dano da bagagem do passageiro ${ }^{36}$.

No momento da aplicação da responsabilidade, não estão incluídos nos limites estabelecidos na Convenção os juros sobre os danos e as custas do processo.

Por fim, é relevante acrescentar que é permitido que o Estado, no momento da assinatura, ratificação, aceitação, aprovação ou adesão a esta Convenção, declare por escrito que não dará efeito a esta Convenção quando o passageiro e/ou o transportador forem súditos ou cidadãos de determinado país. Este ato poderá, a qualquer momento, ser revogado por meio de uma notificação por escrito ao Secretário-Geral da Organização.

Assim, encerra-se a análise sobre a Convenção de Atenas Relativa ao Transporte de Passageiros e às suas Bagagens por Via Marítima, 2002, após uma breve elucidação da responsabilidade civil, dos tratados internacionais e das jurisprudências acerca do tema, seguida, por fim, de uma análise específica deste objeto de estudo, o Protocolo de 2002, o que fez com que a citada convenção se tornasse conhecida como Convenção de Atenas Relativa ao Transporte de Passageiros e às suas Bagagens por Via Marítima, 2002 (Convenção de Atenas 2002).

\section{CONSIDERAÇÕES FINAIS}

O presente artigo teve como objetivo investigar a limitação civil relativa ao transporte de passageiro e suas bagagens por via marítima e a Convenção de Atenas 2002, em face da relevância do tema nos dias atuais, quando dezenas de milhares de passageiros viajam pelo Brasil e mundo afora, saindo e atracando nos portos brasileiros, tornando-se a viagem de cruzeiros um dos meios de transporte mais difundidos nos últimos tempos.

Efetivou-se uma sucinta explanação do conceito de responsabilidade civil, além de esclarecer que o Brasil não assinou e ratificou a Convenção de Atenas de 2002, razão pela qual o sistema judiciário interno utiliza-se das normas relativas ao código de defesa do consumidor, uma vez que se trata de relação de consumo.

Destacaram-se a análise dos tratados internacionais, o seu conceito, o status legislativo que adere no ordenamento jurídico brasileiro e qual é a forma para a sua implementação e executoriedade.

Em seguida, tratou-se de explanar algumas jurisprudências e posicionamentos dos tribunais brasileiros acerca do tema.

Ato contínuo, foi demonstrado quais são os países que haviam aderido a Convenção de Atenas, bem como quais os que já ratificaram a de 2002, porém, como para este segundo caso há apenas 9 países, e é esta a razão pela qual a Convenção de Atenas 2002 ainda não entrou em vigor, uma vez que não se alcançou o número mínimo, que seria de 10 Estados. Importante esclarecer que, além desses países, a União Europeia também já ratificou este protocolo, porém é necessária a tramitação interna para que os países que delam fazem parte passem a aderir esta convenção ${ }^{37}$.

36 Artigo 18, da Convenção de Atenas Relativa ao Transporte de Passageiros e suas Bagagens por Via Marítima, 2002. Disponível em: <https://www.ccaimo.mar.mil.br/sites/ default/files/ Conv_Consolidado_2002.pdf>. Acesso em: 17 ago. 2012.

37 A União Europeia aderiu a Convenção de Atenas de 2002 pelo Regulamento (CE) no 392/2009 do Parlamento Europeu e do Conselho, de 23 de Abril de 2009 sobre a responsabilidade das transportadoras de passageiros por mar em caso de acidente aplicável a partir de 31 de dezembro de 2012. Para uma análise do presente regulamento consultar MARTINEZ GUTIERREZ, Norman A. "Responsabilidad 
Finalizando, falou-se acerca das definições básicas tratadas no acordo, bem como sobre a responsabilidade do transportador e as causas de possibilidade para a limitação da sua responsabilidade, demonstrando quais são as quantias aplicadas.

Assim, verifica-se que, dada a relevância e a atualidade da matéria, seria de sua importância que o Brasil discutisse e aderisse a Convenção de Atenas 2002, a fim de aumentar a segurança jurídica para todas as partes. Ademais, em virtude do Brasil ainda não ter assinado a Convenção de Atenas 2002, há uma escassez de doutrinas acerca do tema, razão pela qual não há necessidade de maior aprofundamento e discussão desse tema.

\section{REFERÊNCIAS}

BRASIL. Código Civil. Disponível em: <http://www.planalto.gov.br/ccivil_03/ leis/2002/L10406compilada.htm>.

. Constituição da República Federativa do Brasil, de 5 de outubro de 1988. Disponível em: <http://www.planalto.gov.br/ccivil_03/constituicao/ constitui\%C3\%A7ao.htm>.

CASTRO JÚNIOR, Osvaldo Agripino de. Direito marítimo: temas atuais. Belo Horizonte: Fórum, 2012.

CONVENÇÃo de Atenas Relativa ao Transporte de Passageiros e suas Bagagens por Via Marítima, 2002. Disponível em: https://www.ccaimo.mar. mil.br/sites/default/files/Conv_Consolidado_2002.pdf.

CONVENÇÃo de Viena sobre o Direito dos Tratados. Disponível em: <http://www.planalto.gov.br/ ccivil_03/_Ato2007-010/2009/Decreto/D7030.htm>.

COTAÇÃO de moedas. Disponível em: <http://www.correios.com.br/ internacional/cfm/cotacao_moedas.cfm>.

CREMONEZE, Paulo Henrique. Prática de direito marítimo: o contrato de transporte marítimo e a responsabilidade civil do transportador.

DINIZ, Maria Helena. Curso de direito civil: Responsabilidade Civil. 18. ed. São Paulo: Saraiva, 2004. v. 7, p. 57.

GAMA, Ricardo Rodrigues. Introdução ao direito internacional. São Paulo: BH, 2006. p.99.

GILBERTONI, Carla Adrina C. Teoria e prática do direito marítimo.

MARTÍNEZ GUTIÉRREZ, Norman A. Limitation of Liability in International Maritime Conventions: The Relationship between Global Limitation Conventions and Particular Liability Regimes. London / New York: Routledge, 2011, 412 p.

MARTÍNEZ GUTIÉRREZ, Norman A. Responsabilidad de los Transportistas de Pasajeros por Mar en Caso de Accidente (La Importancia del Reglamento CE 392/2009), Anuario de Derecho Marítimo, No. 29, 2012 (atualmente em impressão).

MARTÍNEZ GUTIÉRREZ, Norman A.; CASTRO JUNIOR Osvaldo Agripino de. Limitação da responsabilidade civil do prático, p. 43. In: Revista direito aduaneiro e portuário, Vol. 1, n. 5. São Paulo: IOB, 2011.

MORAIS, Alexandre de. Direito constitucional. 22. ed. São Paulo: Atlas, 2004. p. 590.

REZEK, José Francisco. Direito internacional público: curso elementar. 5. ed. São Paulo: Saraiva, 1995. p. 14.

SANTOS, Herez. Introdução ao direito marítimo. Parte integrante da Edição no 24. Disponível em: <http://www.boletimjuridico.com.br/doutrina/texto. asp?id=44>.

Status of conventions as at 31 July 2012. Disponível em: <http://www.imo.org/About/Conventions/ StatusOfConventions/Pages/Default.aspx>.

de los Transportistas de Pasajeros por Mar en Caso de Accidente (La Importancia del Reglamento CE 392/2009)", Anuario de Derecho Marítimo, no 29, 2012 (atualmente em impressão). 